\title{
A DISCUSSÃO DOS DIREITOS REPRODUTIVOS E AS PESSOAS COM DEFICIÊNCIA NA BIOÉTICA UTILISTARISTA
}

\author{
Raimundo Wilson Gama Raiol ${ }^{1}$ \\ Evandro Luan de Mattos Alencar ${ }^{2}$
}

\begin{abstract}
RESUMO: Este artigo tem por objeto de estudo a discussão sobre direitos reprodutivos e as pessoas com deficiência na bioética utilitarista. O problema consiste em como a tradição do utilitarismo, representada na contemporaneidade pelo filósofo Peter Singer, compreende a vida das pessoas com deficiência no contexto dos avanços científicos e biotecnológicos. O objetivo consiste em uma reflexão sobre o posicionamento utilitarista do pensador Peter Singer e suas implicações na discussão bioética dos direitos reprodutivos, em relação à vida e à existência das pessoas com deficiência. A metodologia de pesquisa adotada será a sócio-jurídica de viés qualitativo.
\end{abstract}

Palavras-chave: utilitarismo; direitos reprodutivos; pessoas com deficiência; bioética.

\section{THE DISCUSSION OF REPRODUCTIVE RIGHTS AND PEOPLE WITH DISABILITIES IN UTILISTARIST BIOETHICS}

\begin{abstract}
This article aims to study the discussion on reproductive rights and people with disabilities in utilitarian bioethics. The problem is how the tradition of utilitarianism, represented in contemporary times by the philosopher Peter Singer, understands the lives of people with disabilities in the context of scientific and biotechnological advances. The objective is to reflect on the utilitarian positioning of the thinker Peter Singer and its implications on the bioethical discussion of reproductive rights in relation to the life and existence of people with disabilities. It will be adopted the adopted methodology of research will be methodology adopted will be the socio-legal research of qualitative bias.
\end{abstract}

Keywords: utilitarianism; reproductive rights; disability peoples; bioethics.

\footnotetext{
${ }^{1}$ Advogado. Doutor em Direito pela Universidade Federal do Pará. Professor do Instituto de Ciências Jurídicas da Universidade Federal do Pará, onde leciona na Faculdade de Direito e no Programa de Pós-graduação em Direito. Membro da Academia Paraense de Letras Jurídicas. Atua na linha de pesquisa direitos humanos, bioética e grupos vulneráveis. Mais informações: < http://lattes.cnpq.br/6271053538285645 > E-mail para contato: <raimundoraiolraiol@bol.com.br>

${ }^{2}$ Advogado. Mestrando em Direito pela Universidade Federal do Pará. Especialista em Direito Público pela Pontifícia Universidade Católica de Minas Gerais e Educação em Direitos Humanos na Universidade Federal do Pará. Tem afinidade com temas sobre estudos da deficiência, direitos humanos e bioética. Mais informações: < http://lattes.cnpq.br/3430474424472893 > E-mail para contato: < alencar.ufpa@gmail.com >.
}

Rev. de Biodireito e Direitos dos Animais | e-ISSN: 2525-9695 | Maranhão | v. 3 | n. 2 | p. 95 - 116 | Jul/Dez. 2017 


\section{INTRODUÇÃO}

$\mathrm{Na}$ atualidade, muito se discute sobre direitos reprodutivos. Graças aos avanços da ciência e ao auxílio das técnicas médicas de reprodução assistida, novas dinâmicas têm se estabelecido sobre a concepção da vida humana. No entanto, a temática tem sido abordada com menor ênfase no que concerne à vida e à existência das pessoas com deficiência, em decorrência, dentre outras razões, do desconforto ocasionado por conflitos morais e éticos.

Esse novo cenário apresenta dilemas complexos sobre os quais a bioética se debruça. Questões até então inimagináveis pela ciência renovam a esperança da melhoria de qualidade de vida do homem, mas também apresentam contradições as quais precisam ser analisadas com equilíbrio, com vistas ao bem-estar de nossa espécie. Nesse sentido, a bioética disciplina poderes que podem mudar radicalmente os fundamentos da vida humana e também inflamar problemas, como a exclusão social (GARRAFA, 1998, p. 99).

Nesse contexto, o utilitarismo, como uma alternativa dentro do pensamento bioético, busca estabelecer, a partir dos seus princípios, as fundamentações políticas e filosóficas que sustentam suas pretensões. Seu maior representante na atualidade, como afirmam Diniz e Guilhem (2007, p. 52), é o australiano Peter Singer, professor na Universidade de Princeton, que tem provocado muitas querelas por seus posicionamentos polêmicos, especialmente criticados pelos movimentos sociais das pessoas com deficiência.

Peter Singer é autor de diversas obras, dentre as quais se destacam Ética Prática (1979) e Deve o bebê viver? A questão das crianças deficientes (1988), que apresentam seus argumentos sobre a não-sacralidade da vida humana, o aborto e a sua concepção de pessoalidade do ser humano com deficiência. Afirma Sandel (2012, p. 48), que suas opiniões partem do princípio utilitarista da máxima felicidade, que defende que o objetivo da moral é elevar a felicidade, mas resultam em conclusões que não importam com a diversidade da vida humana, o que tem sido repudiado por ativistas dos direitos das pessoas com deficiência.

Por outro lado, é notória a sedimentação de uma corrente teórica que reconhece a necessidade de fundamentar posicionamentos da bioética atentos às questões sociais e de cidadania, para valorizar os direitos humanos, em decorrência do progresso científico e contemplar também as pessoas com deficiência nos debates de temas controversos que afetam ou afetarão, de alguma forma, a vida delas, como, por exemplo, a eugenia, o aborto seletivo, o determinismo genético e a reprodução humana.

Rev. de Biodireito e Direitos dos Animais | e-ISSN: 2525-9695 | Maranhão | v. 3 | n. 2 | p. 95 -116 | Jul/Dez. 2017 
Logo, a justificativa para perquirir tal tema se dá pela necessidade de aprofundar o entendimento sobre o assunto, dado o contex to supracitado, caracterizado por uma pluralidade de ideias e concepções específicas sobre um mesmo dilema. Além disso, a investigação sobre o assunto é importante para perceber como os princípios do utilitarismo clássico e as suas premissas ainda influenciam as discussões e tomadas de decisões em temas atuais da bioética.

Dessa maneira, o problema enfrentado nesse ensaio pauta-se no questionamento de como a tradição do utilitarismo, representada na contemporaneidade pelo filósofo Peter Singer, compreende a vida das pessoas com deficiência no contexto dos avanços científicos e biotecnológicos. Para responder tal inquietação, o presente artigo objetiva realizar uma reflexão sobre o posicionamento utilitarista do pensador e suas implicações na discussão bioética dos direitos reprodutivos, em relação à vida e as pessoas com deficiência.

A metodologia adotada será a pesquisa sócio-jurídica, proposta por McConville e Chui (2007, p. 77), que busca descrever, explicar e criticar os fenômenos jurídicos, utilizando disciplinas auxiliares como a filosofia moral, a antropologia e a sociologia, para dar respostas ao problema em discussão e dar embasamento substancial ao texto.

A coleta de dados será realizada por meio da técnica de pesquisa de levantamento bibliográfico e documental (SEVERINO, 2010, p.122), que se utiliza de categorias teóricas já trabalhadas por outros pesquisadores em fontes bibliográficas como livros, legislações e revistas científicas especializadas de língua portuguesa, espanhola e inglesa.

Para alcançar os resultados almejados realizar-se-á: i) digressão teórica da bioética, espectro onde se manifesta a maior parte dos conflitos da temática em discussão; ii) visita aos posicionamentos ético-utilitaristas de Peter Singer; e iii) apresentação da argumentação da corrente teórica da bioética social e dos estudos da deficiência sobre a problema.

\section{BIOÉTICA E OS AVANÇOS DA GENÉTICA}

Desde muito a humanidade tem enfrentado problemas morais e éticos sobre a vida, o desenvolvimento humano e o progresso. Essas questões, geralmente, são enfrentadas por filósofos, pensadores e cientistas, que dissertam sobre esses dilemas, a partir de suas perspectivas e premissas particulares, para oferecer orientações razoáveis para a ação humana.

No recente campo de estudo da bioética não é diferente, pois ela é uma área do conhecimento que surgiu como uma proposta de auxiliar, por meio do seu sistema de regras e

Rev. de Biodireito e Direitos dos Animais | e-ISSN: 2525-9695 | Maranhão | v. 3 | n. 2 | p. 95 - 116 | Jul/Dez. 2017 
princípios, na dissolução de problemas éticos, científicos e filosóficos relacionados à vida humana e ao desenvolvimento da tecnologia.

Alarcón (2004, p. 152) afirma que o conceito de bioética foi utilizado, pela primeira vez, por Vans Rensselaer Potter, biólogo da Universidade de Wisconsin, em 1971, no livro intitulado "Bioéthics: bridge to the future", com o sentido de "ser a ciência responsável pela participação racional, porém cautelosa, no processo de evolução biológica e cultural”.

Por conseguinte, foi Warren Reich, na obra "Encyclopedia of bioethics" em 1978, o primeiro autor que afirmou a dimensão sanitária e de ética na científica da bioética ao considerála como o estudo sistematizado da conduta humana, examinada à luz dos princípios e valores morais, na área da ciência da vida e da atenção à saúde (NAMBA, 2015, p. 9).

Ainda assim, é importante frisar a pluralidade de sua extensão teórica, conforme compreende Abel (1989, p. 16) ao afirmar que o "el alcance y amplitude em terreno bioético obliga a renunciar a lo que alguien com fortuna há llamado moral de cercanias. Los limites se extiendem al universo entero y a las futuras generaciones".

Percebe-se que a palavra bioética é um neologismo derivado das palavras gregas bios (vida) e ethike (ética) e define-se como o estudo sistemático das dimensões morais - incluindo visão, decisão, conduta e normas morais - das ciências da vida e da saúde, utilizando uma variedade de metodologias éticas num contexto interdisciplinar (PASSINI, 2006, p. 27).

A bioética, portanto, é um conceito de grande amplitude, que abrange ciência, política, direito e ética, está em constante evolução e representa um estudo acerca da conduta humana no campo da vida, da saúde humana e do perigo da interferência nesse campo pelos avanços das pesquisas biomédicas e tecnocientíficas (FABRIZ, 2003, p. 75).

Para além de uma nova ética científica, a Bioética tem influência na reflexão jusfilosófica acerca dos direitos individuais e coletivos em saúde e na noção de autonomia, o que se reflete nas críticas à faceta paternalista da medicina e na desconstrução do mito da autoridade médica (PORTO, 2014, p. 214). Por isso, é um campo de reflexão que também questiona o poder instituído, desde a relação profissional-paciente e até mesmo aspectos concernentes às políticas públicas de saúde.

Os conflitos práticos e as temáticas específicas da bioética também apresentam uma dimensão política em sua matéria. Nesse sentido, é notória uma dicotomia argumentativa composta por ideais conversadores e liberais, os quais objetivam exprimir o que é importante evitar, promover e apoiar no avanço das tecnologias, em procedimentos de saúde e na extensão prática do estudo da bioética. 
Os posicionamentos conservadores, conforme demonstra Namba (2015, p. 12), são constituídos, em geral, por: i) rejeitar a liberdade do individuo como dimensão principal e objeto dos avanços das técnicas; ii) considerar os problemas individuais e sociais provocados por novas tecnologias, as quais devem ser aplicadas com cautela se não forem devidamente controladas e conhecidas em suas consequências; iii) julgar importante a cautela e necessário aprofundar o conhecimento sobre as técnicas antes de adentrar em campos pouco explorados do conhecimento genético e da manipulação da vida.

De igual maneira, Namba (2015, p. 13) esclarece que os liberais defendem que: i) o indivíduo está acima do caráter público e social, portanto é seu único agente moral; ii) a liberdade individual se sobrepõe à regulação e imposições restritivas estatais; iii) é imperiosa a resolução pacífica de conflitos, com formas jurídicas para tolerâncias e aceitação de casos diversos, bem como considera o homem, enquanto indivíduo, o fim da técnica, dos avanços genéticos e de manipulação da vida.

A questão central das discussões políticas da bioética consiste no debate público da proteção ao direito de liberdade de escolha do indivíduo em oposição à regulamentação das liberdades individuais e dos avanços do conhecimento científico pela moralidade pública e pelos instrumentos normativos estabilizadores de conduta apresentados pelo Direito.

Os posicionamentos dessa discussão se refletem nas diversas correntes que se manifestam na bioética. É importante frisar que, atualmente, se está diante de múltiplos paradigmas da bioética e de diversos modelos teóricos que evidenciam visões antropológicas e filosóficas diferentes, como, por exemplo: o principialista, o liberal-utilitarista, o das virtudes, o do cuidado, o personalista, o social, dentre outros (PESSINI, 2006, p. 22).

A acepção mais difundida acerca da bioética na academia é a estadunidense, proveniente da teoria principialista, cujos marcos conceituais dos princípios da beneficência, da nãomaleficência, da autonomia e da justiça acabaram mais identificados com a disciplina e também por possibilitarem uma ampla interpretação e adequação às questões práticas, bem como contribuírem de grande maneira para o avanço dos debates da bioética.

Dentre as correntes, destaca-se também a visão da bioética utilitarista, percepção que busca fundamentos na doutrina do utilitarismo clássico, desenvolvida por autores como Jeremy Bentham e Jonh Stuart Mill, e tem seu maior representante moderno Peter Singer. O utilitarismo se apresenta como uma ciência da moralidade baseada na quantificação, agregação e no computo geral da felicidade (SANDEL, 2012, p. 55). 
Na América Latina, em oposição ao utilitarismo, é crescente o reconhecimento de uma corrente com dimensão social da bioética pautada na influência da política de direitos humanos, anseio por justiça social e autonomia das pessoas, que procura enfrentar problemas provenientes da exclusão social e com parâmetros socioeconômicos (PORTO, 2014, p. 166).

A corrente da bioética social tem referências em diversos documentos normativos produzidos no âmbito internacional, como a Declaração Universal sobre Bioética e Direitos Humanos, a Declaração Universal sobre o Genoma Humano, a Declaração Internacional sobre Dados Genéticos Humanos, a Convenção para a Proteção dos Direitos Humanos e da Dignidade do Ser Humano relacionada às Aplicações da Biologia e da Medicina, na Declaração de Helsinki, dentre outros.

Nesse sentido, é desse ponto de convergência que nascem as aporias entre a bioética e o direito, pois ambas as áreas do saber são produtos de consenso de forças sociais sobre valores, ideias e pontos de vistas da filosofia moral (ALARCÓN, 2004, p. 157).

No Brasil, essa aproximação pode ser notada na edificação valorativa perante a vida humana e a dignidade existente na Constituição Federal de 1988, bem como em axiomas constitucionais, como o princípio da inviolabilidade e indisponibilidade da vida humana, o da preservação da saúde do ser humano como direito social, da liberdade e consentimento do individuo para as práticas médicas, o da igualdade na lei, o da justiciabilidade, dentre outros.

\subsection{QUESTÕES CONTROVERSAS: DISCRIMINAÇÃO GENÉTICA, EUGENIA E ABORTO SELETIVO}

O tema da manipulação sobre a vida do ser humano tem ocasionado preocupação no âmbito de variadas disciplinas, particularmente na Antropologia, Sociologia e Filosofia, entretanto, é na Bioética e no Biodireito que se encontram a maior parte dos pontos de convergências de estudos (ALARCÓN, 2004, p. 151). A engenharia genética, a biotecnologia e a medicina têm oferecido novas oportunidades e procedimentos controlados para a realização de reprodução humana, o que põe em pauta diversos temas relevantes como melhoramento genético, autonomia reprodutiva e aborto seletivo.

Sandel (2013, p.13) predica que os avanços da genética indicam a possibilidade futura de tratar uma série de doenças debilitantes, como também apresenta o dilema da possibilidade de manipulação da natureza humana, para melhorar a capacidade física, memória, escolher o 
sexo e outras características genéticas dos descendentes. De certo, existe um evidente mal-estar moral quando se trata de engenharia genética e a questão das pessoas com deficiência.

Nesse cenário, novas formas de exclusão se manifestam e emerge a consolidação da bioética social para solucionar esses novos problemas. Esse panorama tecnológico e social ressuscita antigas discussões sobre a humanidade, as quais envolvem aspectos dos direitos reprodutivos, controle populacional e eugenia (AMARAL, 2008, p. 3).

Dessa maneira, a utilização inadequada das informações genéticas podem revelar preconceitos como nas visões pseudocientíficas do reducionismo, determinismo genético, que fortalecem a estigmatização e discriminação por condições genéticas (SEONE RODRIGUEZ apud HAMMERSCHMIDT, 2008, p. 8).

O reducionismo genético é uma concepção que afirma que os genes possuem a explicação para as características de organismos vivos, incluindo os humanos (PENCHASZADEH, 2005, 61). Essa corrente afirma que a saúde e o comportamento social são explicados pelas variações genéticas e não sofrem influência do ambiente. Já o determinismo genético, afirma Echterhoff (2007, p.134), reduz a condição humana ao aspecto gênico, suas informações genéticas e características. Complementa, Mainetti (2003 p. 45), que:

Determinismo genético, es decir, pensar que todo obedece causalmente a los genes, como otrora se responsabilizaba a los astros por el destino4, desconociendo la imbricación de natura y cultura en la cuna del hombre. (MAINETTI, 2003, p.45)

São concepções que levam aos questionamentos do melhoramento genético, pois é muito criticado quando emprega meios medicinais para fins não medicinais. Esse procedimento implica em se tornar um instrumento de melhoria, mas também pode ser uma escolha de consumo ou um direito de aprimorar as características humanas em prol de uma suposta qualidade étnica (SANDEL, 2013, p. 15).

Essas circunstâncias remontam ao movimento eugenista, o qual ambicionava aprimorar geneticamente a raça humana. Seu percursor foi Francis Galton, que almejava realização de reprodução criteriosa durante as diversas gerações para que o homem realizasse de maneira providente os encargos da natureza. Ademais, apresentava também uma dimensão ideológica, pois pretendia ser um objetivo inserido na consciência nacional (SANDEL, 2013, p. 49).

É cediço que a eugenia apresenta argumentos racistas e discriminatórios, pois foi uma política de saúde coletiva que resultou nos fatos históricos mais abomináveis vivenciados pela 
humanidade, desde o descarte de crianças defeituosas em comunidades primitivas, como a morte em massa de judeus no holocausto, lobby para a criação de leis de esterilização, etc.

A literatura jurídica aponta jurisprudências que evidenciam o conflito entre a política eugênica e os direitos humanos, como no caso Buck versus Bell, em que uma mãe solteira de 17 anos foi internada em um sanatório teve de ser submetida à esterilização por decisão de um julgado pela Suprema Corte estadunidense, em 1927 (MUKHERJEE, 2016, p. 71). Em Buck versus Bell, o então elogiado juiz Oliver Wendell Holmes Jr, em seu voto-relatório registrou a sua defesa à legislação de esterilização do Estado da Virgínia, o qual teve o apoio majoritário da corte, decidiu:

É melhor para o mundo todo que, em vez de esperar para executar filhos de degenerados por crimes ou deixá-los morrer de fome vitimados por sua imbecilidade, a sociedade possa impedir os que são manifestamente inaptos de dar continuidade à sua estirpe. O princípio que fundamenta a vacinação compulsória é abrangente o bastante para abarcar o corte das trompas de falópio. Três gerações de imbecis é o suficiente ${ }^{3}$.

Esse paradigma jurídico estadunidense ganhou simpatizantes no continente europeu. Adolf Hitler defendeu a exigência de que os deficientes fossem impedidos de propagar uma prole por considerar um ato humanitário que pouparia milhões de desafortunados de sofrimento e melhoraria da saúde coletiva. A eugenia nazista ultrapassou a esterilização, resultou no assassinato em massa, genocídio e holocausto (SANDEL, 2013, p. 51).

Segundo Meirelles (2014, p.243), o conceito de eugenia apresenta uma percepção histórica que agrega, conforme o progresso das relações humanas, realidades contextualizadas por anseios sociais diferentes. A eugenia clássica buscava, de modo autoritário, produzir cidadãos a partir de um cânone ideal, já a eugenia moderna, d tradição liberal, defende a abstenção do Estado quanto à espécie de filho que os pais desejam ter (SANDEL, 2013, p. 56).

É, decerto, um tema que precisa de aprofundamentos para a solução de casos práticos conexos ao tema, e por isso muitos autores importantes da filosofia política de tradição liberalista não se furtaram a tratar do assunto e apresentam um endosso ao desenvolvimento de uma corrente liberal da eugenia, como Robert Nozick e Jonh Rawls.

\footnotetext{
${ }^{3}$ No original consta: "It is better for all the world, if instead of waiting to execute degenerate offspring for crime, or to let them starve for their imbecility, society can prevent those who are manifestly unfit from continuing their kind. The principle that sustains compulsory vaccination is broad enough to cover cutting the Fallopian tubes. Three generations of imbeciles are enough", ver em Case BUCK vs. BELL (1927) United States Supreme Court. Contemporary issues in Bioethics. Edited by Tom L. Beauchamp \& LeRoy Walters. Belmont (California): International Thomson Publishing, 1994. p. 607-608.
}

Rev. de Biodireito e Direitos dos Animais | e-ISSN: 2525-9695 | Maranhão | v. 3 | n. 2 | p. 95 - 116 | Jul/Dez. 2017 
Robert Nozick (1974, p. 315) apresenta a ideia de supermercado genético que propõe que indivíduos sejam livres para decidir sobre as características de sua prole e realizem melhoramentos genéticos dentro dos limites morais. John Rawls (1971, p. 107) defende que cada indivíduo tenha os melhores bens naturais e a prevenção da difusão de defeitos.

No Brasil, um dos casos emblemáticos recentes que envolve uma discussão sobre bioética e pessoas com deficiência é a ADPF n. 54, julgado pela corte constitucional brasileira que permitiu a realização do aborto de feto com anencefalia ${ }^{4}$. A interrupção da gravidez por anencefalia é uma modalidade de aborto seletivo (DINIZ, 2003, p. 14).

O aborto seletivo ou aborto eugênico é a interrupção da gravidez em decorrência do diagnóstico de uma deficiência, diferença ou anomalia fetal identificado no meio do exame prénatal (DINIZ, 1997, p.01). São abortos realizados em razão de valores eugênicos, que levam em consideração critérios racistas, sexistas e étnicos, que remetem a uma prática comumente adotada na medicina nazista (DINIZ e ALMEIDA, 1998, p. 126).

Os exames de diagnósticos pré-natal, como a ecografia e a amniocentese, podem detectar deformações congênitas, físicas, nervosas e transtornos genéticos com aproximada exatidão (LOWY, 2011, 105). Essas técnicas aliadas à posição ético-utilitarista implicaram em repercussões práticas que evidenciam o aumento da interrupção eugênica da gravidez.

Alguns fatos podem ser citados, como no Reino Unido ${ }^{5}$ que $90 \%$ das pessoas decidem abortar ao identificar a possível existência de um transtorno genético; na Islândia ${ }^{6}$ é quase zero a incidência de nascimento de crianças com síndrome de down; na Nova Zelândia ${ }^{7}$ a ONG "Saving downs" acusa, no Tribunal de Justiça Internacional, o governo local de instituir uma política econômica de custo-benefício para a realização do aborto seletivo de crianças com transtornos genéticos; a França ${ }^{8}$ proibiu a propaganda para persuadir mulheres ao valor da vida com down; no Brasil ${ }^{9}$, se discute a legalização do aborto seletivo para mulheres que foram infectadas com zika vírus e que seus fetos tenham sequelas, como a microcefalia.

\footnotetext{
${ }^{4}$ Marco Aurélio Mello: Decisão histórica do STF permite aborto de anencéfalo. jun. 2015. Disponível em: $<$ http://goo.gl/PZ3i4i>. Acesso em: 22 jun. 2017.

${ }^{5}$ La prueba médica que podría acabar con el síndrome de Down (y por qué algunos no quieren que eso ocurra). jun. 2017. Disponível em:< http://www.bbc.com/mundo/noticias-37524744>. Acesso em: 22 jun. 2017.

6 Islândia é responsável por genocídio dos Síndrome de Down. mar. 2017. Disponível em: $<$ http://estudosnacionais.com/islandia-e-responsavel-por-genocidio-dos-sindrome-de/>. Acesso em: 22 jun. 2017.

${ }^{7}$ Na Nova Zelândia, grupo de pais busca frear o "genocídio" de pessoas com síndrome de Down. set. 2011. Disponível em: <http://www.inclusive.org.br/arquivos/21124>. Acesso em: 22 jun. 2017.

${ }^{8}$ França proíbe vídeo sobre valor da vida com down. nov. 2016. Disponível em: <goo.gl/V3hcgr>. Acesso em: 22 jun. 2017.

${ }^{9}$ Possibilidade de legalização do aborto em casos de microcefalia divide opiniões. jun. 2016. Disponível em: $<$ https://goo.gl/HBFQG6>. Acesso em: 22 jun. 2017.
} 
Essa entendimento, tido no mundo todo, origina da opinião de autores que tentam fundamentar o reconhecimento jurídico da prática do aborto eugênico. Dip (1996, p. 522), por exemplo, apresenta a ideia de que o direito de nascer e viver somente deve ser atribuído à sadios físicos e mentais, vez que os enfermos serão infelizes e farão sofrer terceiros.

A discriminação genética, a eugenia e o aborto seletivo são temas arriscados que impõem um sentimento de perigo representado por uma antropotécnica política, cuja finalidade pode ser a criação sistemática de exemplares humanos mais próximos de protótipos assim dito ideais (SLOTERDIJK, 2000, p. 50).

Nesse panorama, a concepção jurídica de pessoa humana, até então pacificada e presente no direito positivo, é posta em questionamento pelo novo mundo construído pela engenharia genética e cria uma tensão de entendimento de conceitos jurídicos elementares de sujeito de direito (BARRETO, 2003, p. 220). É nesse cenário que se insere a discussão da deficiência e do utilitarismo, principal corrente que apresenta argumentos sobre a valoração da vida com deficiência, a moralidade do aborto e da relação custo-benefício dessa modalidade de existência da vida, aspectos que veremos no tópico a seguir.

\section{TRADIÇÃO UTILITARISTA E A BIOÉTICA}

O utilitarismo é uma corrente filosófica com fins práticos, de vez que sempre se apresentou como uma proposta de regulação das relações humanas, políticas estatais e conflitos morais das decisões que circundam o convívio dos seres humanos em sociedade.

As contribuições utilitaristas na bioética, em geral, consistem na formação e no enriquecimento da fundamentação das dimensões individuais dos princípios da autonomia e da beneficência (CLOTET, 2003, p. 176-177), bem como nas recomendações práticas para a importância do exercício da verdade na relação médico-paciente e também na questão moral da utilização de animais em experimentos genéticos.

A doutrina do utilitarismo é uma ética consequencialista que prega que as coisas devem ser medidas conforme suas consequências possíveis, e, além disso, compreende a utilidade ou a felicidade como o valor moral que deve ser elevado o máximo possível (BUNNIN, TSUIJAMES, 1996, p. 628). Nesse sentido, explica John Stuart Mill:

A doutrina que aceita como fundamento da moral a utilidade, ou o princípio da felicidade maior, defende que as ações são corretas na medida em que tendem a promover a felicidade, e incorretas na medida em que tendem a gerar o contrário da 
felicidade. Por felicidade se entende o prazer e ausência de dor; por infelicidade, a dor e a privação do prazer (MILL, 2005, p. 52).

Os principais representantes do utilitarismo são Jeremy Bentham, John Stuart Mill e, mais recente, Peter Singer. Seu fundador foi Jeremy Bentham (1748-1832), filosofo moral, que inaugurou a doutrina com a ideia central de que o mais elevado objeto da moral é maximizar a felicidade, assegurando a hegemonia do prazer sobre a dor. Dessa forma, para Bentham, a coisa certa a fazer é aquela que maximizará a utilidade, definida como aquilo que produz prazer ou felicidade e que evite a dor ou o sofrimento (SANDEL, 2012, p. 48).

Jonh Stuart Mill tentou revisar a doutrina de Bentham e tornar o utilitarismo uma corrente mais humana com intuito de conciliá-la com os direitos individuais (SANDEL, 2012, p.64) e inseriu a ideia de que o mais importante não é a felicidade do indivíduo, mas a quantidade maior de felicidade do maior número de pessoas (MILL, 2005, p. 64).

Mill também defendia que existem limites à soberania do governo em interferir na esfera individual do cidadão, bem como apresenta o princípio do dano, na qual apregoava que todo indivíduo deveria respeitar os direitos dos demais indivíduos com o fim de que sua conduta não resulte em um dano (MILL, 2007, p. 106).

Peter Singer (2002, p.11) explica que o utilitarismo é uma das teorias consequencialistas mais adotadas até os dias atuais. É uma doutrina em que seus adeptos não decorrem suas ações de regras morais, mas de anseios que fundamentam a qualidade das suas ações em prol de seus objetivos.

O utilitarista clássico admite uma ação correta ou errada quando a compara com uma ação alternativa e afere a que produz maior quantidade de felicidade a todos que por ela serão atingidos, e, por isso, no utilitarismo, as consequências de uma ação variam conforme as circunstâncias praticadas (SINGER, 2002, p. 11). Já o utilitarismo moderno apresenta como seu maior pensador Peter Singer, filósofo australiano, que produziu grandes influências para discussões do pensamento bioético, conforme exposto a seguir.

\subsection{BIOÉTICA UTILITARISTA DE PETER SINGER}

A principal obra de Peter Singer, em língua portuguesa, sobre o tema da bioética é “Ética Prática" (2002), trabalho onde o autor reuniu seus maiores escritos sobre os temas correlatos ao utilitarismo, aborto, pessoas com deficiência e demais temas da filosofia moral. Singer apresenta uma ideia sofisticada e um raciocínio atrativo, e por isso muitos intelectuais e pensadores 
modernos concordam com parte de seus argumentos, embora não se filiem à sua corrente filosófica de maneira direta.

Peter Singer (2002 p. 10,) admite ter recebido diversas críticas pela divulgação de seu trabalho, em especial, na sua conturbada passagem pela Alemanha, na década de 80 , ocasião em que ocorreram protestos de ativistas dos direitos das pessoas com deficiência e cancelamento de palestras.

É um autor que costuma se apresentar como incompreendido, por receber muitas críticas de leitores que encontram seus argumentos expostos e descontextualizados em artigos científicos dispersos. Entretanto, seu discurso apresenta uma noção conflitiva em relação ao ideal de proteção das pessoas com deficiência que merece ser melhor abordada.

Singer (2002, p. 26) apresenta críticas à atual concepção de igualdade que a apregoa como uma ideia absoluta entre os seres humanos. Dessa maneira, o autor sustenta-se em Rawls para fundamentar que os seres humanos são diferentes entre si, pois, apresentam concepções de moral e justiça plurais.

É a partir dessa percepção que Singer (2002, p. 28-29) afirma que nem todos os seres humanos são pessoas morais, vez que as pessoas com problemas mentais, os bebês e as crianças carecem de um senso de justiça, logo não são iguais aos demais, pois diferem enquanto indivíduo.

Nesse sentido, Singer (2002, p. 30) apresenta o seu princípio da igualdade de interesses, o qual apregoa que a todo interesse deve ser considerado e atribuído peso igual e, dessa forma, questões como raça, sexo, capacidade intelectual ou moral são secundárias para a consideração dos interesses. É uma concepção que não advoga a igualdade entre as pessoas, mas entre os seus interesses, os quais serão mitigados um em prol do outro.

Peter Singer aparenta ter interesse de afastar as bases científicas da moral que identifica a ideia de igualdade enquanto absoluta e impeditiva de afirmar as diferenças biológicas sem que sejam reconhecidas como considerações éticas e políticas sexistas e racistas ou discriminatórias.

Ainda assim, o autor trata de dissertar sobre a questão da igualdade e a deficiência, a respeito do que em primeiro momento reconhece a justificativa da adoção de ações afirmativas e a necessidade de igualdade de condições com as demais pessoas, sob a ótica do princípio do igual interesse (SINGER, 2002, p. 63).

Entretanto, disserta o autor que muitos confundem seu posicionamento inicial com a sua proposta para justificar os argumentos do aborto e do infanticídio de pessoas com deficiência, uma vez que defende que a vida com deficiência é inferior, causa dor, sofrimento e ninguém 
desejaria ter uma prole com deficiência como interesse da sua felicidade (SINGER, 2002, p. $64)$.

Singer também se dedica-se a apresentar seus argumentos sobre a prática do aborto, que reconhece como tema delicado da filosofia moral. Ele defende que o óvulo fertilizado é uma célula única que depois de vários dias não deixou de ser um aglomerado de células sem características anatômicas do ser em que se transformará (SINGER, 2002, p.147).

Na oportunidade, Singer também discute sobre status do feto e apresenta sua visão sobre a questão a partir dos argumentos conservadores e liberais, para posteriormente adentrar em uma discussão mais ampla sobre o valor da vida e os aspectos correlacionados com o aborto seletivo e o infanticídio de crianças.

Para além do debate tradicional sobre o aborto com fundamentos na autonomia reprodutiva da mulher, momento de concepção da vida e a da ética religiosa, temas que não são objetivos da discussão desse trabalho (e também por acreditar que é mais salutar dar importância para os resultados práticos do que aos discursos retóricos), descrever-se-á a percepção de pessoalidade de Peter Singer e sua visão moral de vida com deficiência.

Assim, Singer (2002, p. 191) disserta sobre as decisões de vida e morte nos casos dos bebês deficientes e apresenta razões pela qual defende o aborto e o infanticídio como meios de alcançar o objetivo utilitarista de diminuir o sofrimento e a sacralidade da vida humana.

Peter Singer, (2002, p. 192) afirma que algumas deficiências apresentam questões mais triviais, mas, no geral, os país apresentam motivos consistentes para lamentar o nascimento de uma criança deficiente, os quais justificam a morte da criança com deficiência.

O autor defende que os bebês são seres sencientes, que não são seres racionais, nem autoconscientes, por isso não são relevantes para o status moral da sua espécie (SINGER, p. 193). Por isso, o autor afirma que quando a vida de um bebê com deficiência vai ser tão miserável que não valerá a pena viver, o utilitarismo apresentará argumentos favoráveis ao seu extermínio em prol do não sofrimento e rejeição da dor.

Singer (2002, p.195) afirma que existe uma perspectiva de que a vida de uma criança normal será significativamente mais feliz que uma criança com alguma deficiência grave. Portanto, à luz do utilitarismo, a vida da criança com o dito padrão normal da espécie apresenta uma carga valorativa maior do que a vida de uma criança com deficiência.

$\mathrm{O}$ autor admite a dificuldade de que a moralidade atual vai compreender a morte de uma criança com deficiência longe do espectro do assassinato. Peter Singer adentra na questão do diagnóstico pré-natal e afirma que fetos identificados com hemofilia, síndrome de down e outros

Rev. de Biodireito e Direitos dos Animais | e-ISSN: 2525-9695 | Maranhão | v. 3 | n. 2 | p. 95 - 116 | Jul/Dez. 2017 
transtornos genéticos são comumente abortados e que essa deveria ser uma prática aceitável, pois seria superada pela conquista de uma futura vida melhor para uma criança normal (SINGER, 2002, p. 197).

Dessa maneira, Peter Singer (2002, p. 199) busca esclarecer que o seu posicionamento não implica em falta de respeito ou igual consideração pelas pessoas com deficiência, mas acredita ser razoável que os país pudessem ser capazes de tomar essa decisão que resultaria no aborto seletivo.

Portanto, Singer (2002, p. 200) demonstra seu posicionamento ao afirmar que, para o utilitarismo, tirar a vida de um bebê deficiente não equivale, moralmente, a tirar a vida de um bebê normal e que essa prática não deveria representar erro algum. Diniz e Guilhem (2007, p. 53) sintetizam seu entendimento ao afirmar que um bebê com deficiência não tem garantido o seu caráter de pessoalidade, pois não tem capacidade de relacionamento social, noção de tempo histórico, linguagem e atributos que um ser vivo com consciência possa desenvolver.

\section{PESSOAS COM DEFICIÊNCIA, BIOÉTICA SOCIAL E DIREITO REPRODUTIVOS}

A visão da bioética social critica o raciocínio utilitarista de que só é útil aquilo que está adequado às suas diretrizes de custo e benefício e promoção de felicidade. Esse raciocínio implica em afirmar que pessoas que demandem custos para a sociedade, como as que perderam condições físicas e mentais ou que não possam integrar a sociedade de maneira eficiente sejam rotuladas como inúteis e descartáveis (JUNQUEIRA, 2011, p. 13).

Desde muito, como aponta Sandel (2012, p. 51), o utilitarismo é criticado por não respeitar os direitos individuais e tratar o indivíduo com menor importância. Por isso, se a bioética utilitarista fosse aplicada de maneira consistente nas questões atuais controversas discutidas nesse trabalho, iria implicar em inúmeras violações do que se compreende como normas fundamentais éticas de respeito ao trato humano.

Atualmente, as ferramentas teóricas e conceituais para o estudo da bioética em uma dimensão social ainda estão sendo delimitadas, mas a questão da desigualdade social e justiça transgeracional entre segmentos, grupos, populações e sociedades já foi muito identificada como cerne da reflexão na dimensão coletiva, principalmente no que tange ao acesso à saúde e à qualidade de vida (PORTO, 2014, p. 217). 
Nesse sentido, idosos, crianças com problemas mentais e pessoas com deficiências em geral que estejam em situação de vulnerabilidade devem ser respeitadas, amparadas e defendidas pelas políticas públicas de inclusão e de manutenção de uma vida digna.

Entretanto, alguns bioeticistas defendem que a experiência da vida com deficiência implica em viver em desvantagem e por isso deve ser inviabilizado seu nascimento por promover um estado de degradação humana, de infelicidade e de elevado custo-benefício para a sociedade (WATSON apud ASCH, 2003, p. 62).

É inegável que uma vida com deficiência possa compartilhar de dor física, desgaste emocional, exclusão econômica e social, entretanto a maior parte da experiência negativa vivenciada parte muito mais do comportamento inapropriado e despreparado da sociedade em geral, do que da condição de existência biológica.

Nesse sentido, a ativista Adrienne Asch (2003, p. 60) contraria a percepção médicoutilitarista da deficiência e afirma que a vida com deficiência vale a pena ser vivida, além do que uma sociedade justa e inclusiva deve promover a pluralidade da vida de todas as pessoas. independentemente de sua condição individual, social, econômica, biológica e genética. As pessoas com deficiência também têm muito à oferecer para a sua comunidade e contribuir com talento, personalidade e humanidade.

É nesse sentido que as novas descobertas da área da genética reprodutiva humana se aproximam do discurso dos direitos humanos, vez que se evidencia que devem ser pautadas no princípio da não-discriminação, da proteção da pessoa com deficiência e na preservação integral desses direitos humanos.

Portanto, o desenvolvimento científico e tecnológico na área de genética humana e o constante uso de novas técnicas na medicina reprodutiva também se refletem na importância da realização de um diálogo entre as ciências da vida, da saúde e do direito. Nesse sentido, as discussões bioéticas possibilitam uma expansão e aprimoramento dos direitos reprodutivos, aspectos que serão vistos, a seguir.

\subsection{DIREITOS REPRODUTIVOS, VULNERABILIDADE E PESSOAS COM DEFICIÊNCIA}

Segundo Mattar (2008, p.63), o termo "direitos reprodutivos" foi usado pela primeira vez no I Encontro Internacional de Saúde da Mulher realizado em Amsterdã, Holanda, em 1984, após o consenso de que essa nova denominação traduzia um conceito mais completo do que “saúde da mulher", pois se constitui campo teórico para além da pauta feminista. 
A maior referência na literatura especializada é o relatório da Conferência Internacional sobre População e Desenvolvimento, conhecida por Programa do Cairo, de 1994. Nesse documento, restou estabelecido que direitos reprodutivos tivessem ampla ligação com aspectos da saúde coletiva e delimitou em seu item 7.3 que:

[...] Esses direitos se baseiam no reconhecido direito básico de todo casal e de todo indivíduo de decidir livre e responsavelmente sobre o número, o espaçamento e a oportunidade de seus filhos e de ter a informação e os meios de assim o fazer, e o direito de gozar do mais alto padrão de saúde sexual e de reprodução. Inclui também seu direito de tomar decisões sobre a reprodução, livre de discriminação, coerção ou violência, conforme expresso em documentos sobre direitos humanos. No exercício desse direito, devem levar em consideração as necessidades de seus filhos atuais e futuros e suas responsabilidades para com a comunidade. [...] (Nações Unidas, Plataforma de Cairo, 1994).

Os direitos sexuais e reprodutivos correspondem a um conjunto básico de direitos relacionados ao livre exercício da sexualidade e da reprodução humana. Esse conceito compreende o acesso à saúde, mediante o que se assegure informações, educação e meios, tanto de controle de natalidade quanto para a reprodução, sem riscos para a sanidade física, mental e psicológica, bem como para a vida humana (PIOVESAN, 2012, p. 214).

Dessa maneira, é possível afirmar que os direitos reprodutivos e sexuais são direitos humanos fundamentais, universais e indisponíveis, reconhecidos pelas leis internacionais e nacionais que fundamentam os direitos e obrigações do Estado para com os cidadãos em relação à reprodução e o exercício da sexualidade (VENTURA, 2004, p. 19).

Os direitos reprodutivos, enquanto direitos humanos, foram recepcionados pela Constituição Federal de 1988 e encontram-se registrados em diversos dispositivos legais, com destaque ao conteúdo elencado como direitos e garantias fundamentais. A constitucionalização desses direitos advém de uma ampla interpretação acerca da pessoa humana no contexto do Estado Democrático de Direito e ao livre exercício de autodeterminação, autonomia e também como meio de afirmação individual do sujeito na sociedade.

Torna-se relevante citar que a temática dos direitos reprodutivos expande-se com as novas possibilidades proporcionadas pela engenharia genética e o desenvolvimento por ela alcançado ao manipular tecnicamente as informações genéticas e esses avanços deparam-se com as mitigações impostas pelos direitos das pessoas com deficiência.

É cediço que as pessoas com deficiência sempre existiram no espaço da sociedade e, portanto, sua presença não é um fenômeno recente nas mais diversificadas culturas globais, ainda que cada qual reserve tratamento variado na recepção das pessoas com deficiência como 
a rejeição, o assistencialismo e a integração de maneira tímida, mediante sua readaptação (NEUMANN e ALGERICH, 2004, p. 121). Muito do que se afirma sobre esse segmento de social decorre da visão do capacitista, constituída da ideia que as pessoas com deficiência são inferiores, o que causa na discriminação e pelo preconceito social (CAMPBELL, 2008, p. 02).

Os sanitaristas compreendem a deficiência como algo que deve ser extirpado da sociedade, pois a consideram como algo incompatível com uma vida satisfatória, e, por isso, eles objetivam curar ou erradicar o surgimento de deficiências (ASCH, 2003, p. 53), entretanto, a grande maioria das barreiras ligadas à vida com deficiência decorre de arranjos sociais discriminatórios que podem ser mitigados para promoção de uma vida digna.

Nesse sentido, as pessoas com deficiência compõem uma parcela considerável da população mundial e brasileira, logo, um contingente populacional que justifica a necessidade de promover ações de inclusão social (NONATO e RAIOL, 2015, p. 84), de criação de política de proteção contra qualquer situação de vulnerabilidade, inclusive as de aspecto médico, reprodutivo e genético.

Sua disposição mais relevante no ordenamento jurídico brasileiro está no Artigo $6^{\circ}$ da Lei $n^{\circ}$ 13.146, de 06 de julho de 2015, conhecida como Lei Brasileira de Inclusão ou Estatuto da Pessoa com Deficiência, preceitua a plena capacidade civil da pessoa com deficiência para exercer seus direitos sexuais e reprodutivos, decidir sobre o número de filhos, ter informações adequadas sobre reprodução, realizar planejamento familiar e conservar sua fertilidade.

Como essa questão não está alheia ao fenômeno da globalização e aos interesses dos Estados-Nações, muito foi produzido no âmbito do direito internacional dos direitos humanos com fulcro de administrar o status normativo e recomendações jurídicas sobre o tema. Os principais documentos internacionais: a) a Convenção Internacional sobre os Direitos das Pessoas com Deficiência; b) a Declaração Universal de Bioética e dos Direitos Humanos; e c) Declaração Universal sobre o Genoma Humano, dentre outros instrumentos.

O mais importante avanço na concretização de uma política protetiva de pessoas com deficiência foi alcançado na Convenção Internacional sobre os Direitos das Pessoas com Deficiência e seu Protocolo Facultativo, assinados em Nova York, em 30 de março de 2007, em trabalhos dirigidos pela Organização das Nações Unidas.

A Convenção da ONU sobre os Direitos das Pessoas com Deficiência surge como uma resposta para as necessidades das comunidades internacionais frente ao considerável histórico de discriminação, exclusão e desumanização das pessoas com deficiência (PIOVESAN, 2013, p. 47). O texto do documento internacional citado apresenta uma reserva especial sobre a 
proteção aos direitos reprodutivos de forma ampla e abarcou questões correlatas, como se vê no artigo 23, itens a, b e c, in verbis:

Os Estados Partes tomarão medidas efetivas e apropriadas para eliminar a discriminação contra pessoas com deficiência, em todos os aspectos relativos a casamento, família, paternidade e relacionamentos, em igualdade de condições com as demais pessoas, de modo a assegurar que: a) Seja reconhecido o direito das pessoas com deficiência, em idade de contrair matrimônio, de casar-se e estabelecer família, com base no livre e pleno consentimento dos pretendentes; b) Sejam reconhecidos os direitos das pessoas com deficiência de decidir livre e responsavelmente sobre o número de filhos, o espaçamento entre esses filhos e de ter acesso a informações adequadas à idade e a educação em matéria de reprodução e de planejamento familiar, bem como os meios necessários para exercer esses direitos. c) As pessoas com deficiência, inclusive crianças, conservem sua fertilidade, em igualdade de condições com as demais pessoas.

A Declaração Universal sobre o Genoma Humano tratou o problema de maneira mais particular e reservou um artigo para registrar uma política de cooperação internacional e solidariedade especial à grupos vulneráveis, dentre esses as pessoas com deficiência, a saber:

Artigo 17 - Os Estados devem respeitar e promover a prática da solidariedade com os indivíduos, as famílias e os grupos populacionais que são particularmente vulneráveis a, ou afetados por, doenças ou deficiências de caráter genético. Eles devem fomentar pesquisas "inter alia" sobre a identificação, prevenção e tratamento de doenças de fundo genético e de influência genética, em particular as doenças raras e as endêmicas, que afetam grande parte da população mundial.

Já a Declaração Universal sobre Bioética e Direitos Humanos apresentou uma redefinição das diretrizes dos estudos e avanços sobre a genética, com viés de conferir uma faceta social e política para as discussões científicas, como se percebe da citação a seguir:

Artigo 3 - Dignidade Humana e Direitos Humanos: a) A dignidade humana, os direitos humanos e as liberdades fundamentais devem ser respeitados em sua totalidade. b) Os interesses e o bem-estar do indivíduo devem ter prioridade sobre o interesse exclusivo da ciência ou da sociedade.

$[\ldots]$

Artigo 8 - Respeito pela Vulnerabilidade Humana e pela Integridade Individual: A vulnerabilidade humana deve ser levada em consideração na aplicação e no avanço do conhecimento científico, das práticas médicas e de tecnologias associadas. Indivíduos e grupos de vulnerabilidade específica devem ser protegidos e a integridade individual de cada um deve ser respeitada.

$[\ldots]$

Artigo 11 - Não-Discriminação e Não-Estigmatização: Nenhum indivíduo ou grupo deve ser discriminado ou estigmatizado por qualquer razão, o que constitui violação à dignidade humana, aos direitos humanos e liberdades fundamentais. 
O documento abarcou noções de dignidade humana, respeito aos grupos vulneráveis, integridade pessoal, igualdade, diversidade e justiça. Por isso, foi responsável por inserir pautas mais voltadas para as necessidades humanas e o respeito à política e cultura de preservação dos direitos humanos nas novas discussões da bioética.

\section{CONCLUSÃO}

É possível concluir que a bioética é a ciência responsável pela regulamentação de temas correlatos à manipulação da vida humana, dos avanços biotecnológicos; é nela que se expressam as correntes da filosofia moral que fundamentam as práticas ético-médicas. É uma disciplina que deve ser considerada como segmento de estudo prioritário para inserção de mais literaturas especializadas ligadas à tradição sociológica de estudos da deficiência, uma vez que a bioética também representa um campo de exercício de poder entre as suas correntes.

Também é desejável que os avanços genéticos sejam pautados em uma percepção bioética que busque meios de promover a saúde e a qualidade de vida para as pessoas em geral, em especial das pessoas com deficiência. Todavia, é imperioso evitar práticas que incentivem a grande interferência nos ciclos naturais da experiência humana na concepção de uma vida e de posicionamentos que incentivem o aborto seletivo em decorrência da descriminação da condição biológica.

O utilitarismo apresenta-se incompatível com a política de direitos humanos e proteção aos direitos individuais. Ademais, a argumentação proposta por Peter Singer sobre as pessoas com deficiência necessita ser refutada com argumentação coerente e bem embasada, apesar de o autor ter apresentado racionalidade sofisticada e sedutora, razão pela qual influenciou grandes segmentos da bioética.

É importante frisar que existem posicionamentos salutares que consideram a vida com deficiência enquanto expressão da diversidade humana e não com status de menos vida que o dito padrão normal da espécie. Essa lamentável concepção de inferioridade existencial é provocada pela falta de informações adequadas sobre a deficiência, por influência do capacitismo e, também, pela propagação do utilitarismo no campo da ética médica.

Portanto, é preciso ter cautela e evitar que se "genetize" e reduza as pessoas à sua condição humana genética, por mais que isso provoque custos, incômodos e receios de vivenciála. A aceitação da deficiência também como estilo de vida, com aspectos culturais, políticos e 
sociais particulares é importante para combater o mais danoso tipo de preconceito, que, de modo silencioso, alia a discriminação com a técnica médica.

\section{REFERÊNCIAS}

ABEL, Francecs. Introducción bioética: origen y desarrolho. Madrid: U.P Comillas, 1989.

ASCH, Adrienne. Diagnóstico pré-natal e aborto seletivo: Um desafio à prática e às políticas. Physis, Rio de Janeiro, v.13, n. 2, Dez. 2003.

ALARCÓN, Pietro de Jesús Lora. Patrimônio Genético Humano e a sua proteção na Constituição Federal de 1988. São Paulo: Editora Método, 2004.

AMARAL, Aécio. Ética do discurso e a eugenia liberal: Jurgen Habermas e o futuro da natureza humana. Liinc em Revista, 4(1), 2008.

BARRETO, Vicente de Paulo. A ideia de Pessoa Humana: os Limites da Bioética In: BARBOZA, Heloisa Helena; MEIRELLES, Jussara Maria Leal de; BARRETO, Vicente de Paulo. Novos temas de biodireito e bioética. Rio de Janeiro: Renovar, 2003.

BARROS, Alessandra. Limites à condenação do aborto seletivo: a deficiência em contextos de países periféricos. Physis, Rio de Janeiro, v.13, n.2, p. 273-286, Dez. 2003.

BUNNIN, Nicholas e TSUI-JAMES, E.P. The Blackwell Companion to Philosophy. Oxford - United Kingdom: Blackwell Publisher, 1996.

CAMPBELL, Fiona Kumari. Refusing Able(ness): A Preliminary Conversation about Ableism. Media Culture Journal. Vol. 11. N 3. 2008.

Case BUCK vs. BELL (1927) United States Supreme Court. Contemporary issues in Bioethics / edited by Tom L. Beauchamp \& LeRoy Walters. Belmont (California): International Thomson Publishing, 1994.

DINIZ, Débora. Apresentação: diagnóstico pré-natal e aborto seletivo. Physis, Rio de Janeiro, v.13, n. 2, Dez. 2003.

. Quem autoriza o aborto seletivo no Brasil? Médicos, promotores e juízes em cena. Physis, Rio de Janeiro, v.13, n. 2, Dez. 2003.

. Aborto seletivo no Brasil e os alvarás judiciais. Revista Bioética. v.5, n.1, 1997.

DINIZ, Débora; GUILHEM, Dirce. O que é bioética? São Paulo: Editora Brasiliense, $3^{\mathrm{a}}$ impressão. 2007.

DIP, Ricardo Henry Marques. Uma questão biojurídica fundamental: a autorização judicial de aborto eugenésico - alvará para matar. São Paulo: Editora RT, 1996.

ECHTERHOFF, Gisele. A terapia gênica e a eugenia. Revista da AJURIS. v.36, n.114, 2009.

Rev. de Biodireito e Direitos dos Animais | e-ISSN: 2525-9695 | Maranhão | v. 3 | n. 2 | p. 95 - 116 | Jul/Dez. 2017 
FABRIZ, Daury Cesar. Bioética e Direitos Fundamentais: A bioconstituição como paradigma do biodireito. Belo Horizonte, Editora Mandamentos, 2003.

GARRAFA, Volnei. Bioética e Ciência: Até onde avançar sem agredir. In: COSTA, Sérgio Ibiapana Ferreira; GARRAFA, Volnei; OSELKA, Gabriel (Org.) Iniciação à Bioética. Brasília: Conselho Federal de Medicina, 1998.

HAMMERSCHMIDT, Denise. Direito e discriminação genética. Revista do Direito Privado da UEL. v. 1 n. 2 Mai-Ago/2008.

JUNQUEIRA, Cilene Rennó. Bioética: conceito, fundamentação e princípios. São Paulo: Unifesp, 2011.

LOWY, Ilana. Detectando más-formações, detectando riscos: dilemas do diagnóstico prénatal. Horizontes antropológicos. Porto Alegre, v.17, n. 35, Jun/2011.

MATTAR, Laura Davis. Reconhecimento jurídicos dos direitos sexuais - uma análise comparativa com os direitos reprodutivos. Revista Sur - Direito internacional dos direitos humanos. São Paulo. ano 5, n.8, Jun/2008.

MAINETTI, José Alberto. Bioética y genómica. Acta bioeth. Santiago, v. 9, n. 1, 2003.

McCONVILLE, Mike; CHUI, Wing Hong. Research methods for law. Edinburgh: Edinburgh University Press. 2007.

MEIRELLES, Ana Thereza. Possibilidades neoeugênicas em procriação humana artificial e preservação do patrimônio genético. In: MEZZAROBA, Orides; et all. Biodireito. Coleção Conpedi. Curitiba: Editora Clássica, 2014.

MUKHERJEE, Siddhartha. O gene - Uma história íntima. São Paulo: Companhia das Letras, 2016.

MILL, John Stuart. Utilitarismo. Lisboa - Portugal: Editora Gradiva, 2005.

NEUMANN, Katiúscia e ALGERICH, Eloisa Nair de Andrade. A situação da pessoa com deficiência em relação à sociedade, ontem e hoje. Revista Direito em Debate, n.21, 2004.

NOZICK, Robert. Anarchy, State, and Utopia. Oxford: Blackwell Publishers Ltda, 1974. . Sobre a liberdade. Lisboa - Portugal: Edições 70. 2006.

NAMBA, Edison T. Manual de bioética e biodireito. $2^{\text {a }}$ ed. São Paulo, Ed. Atlas, 2015.

NONATO, Domingos do Nascimento; RAIOL, Raimundo Wilson Gama. PERSPECTIVAS DA DIGNIDADE HUMANA À LUZ DA CONVENÇÃO DA ONU SOBRE OS DIREITOS DAS PESSOAS COM DEFICIÊNCIA. Revista de Direito Brasileira, v. 10, n. 5, abr. 2015. 
PENCHASZADEH, Victor B. Problemas éticos do determinismo genético. Revista Bioética. V.12 n, 1

PESSINI, Léo. Bioética: um grito por dignidade de viver. São Paulo: Ed. Paulinas, 2006.

PIOVESAN, Flávia. Temas de Direitos Humanos. 5a ed. São Paulo: Editora Saraiva, 2012.

PORTO, Dora. Bioética na América Latina: desafio e poder hegemônico. Revista Bioética, v.22 n.2, 2014.

RAWLS, John. A theory of justice. Cambridge: Harvard University Press, 1971.

SANDEL, Michael. Justiça: O que é fazer a coisa certa? $6^{a}$ ed. Rio de Janeiro: Civilização Brasileira, 2012.

. Justiça: Contra a perfeição: Ética na era da engenharia genética. Rio de Janeiro: Civilização Brasileira, 2013.

SEVERINO, Antonio Joaquim. Metodologia do Trabalho Científico. $3^{\mathrm{a}}$ ed. São Paulo: Cortez Editora, 2010.

SINGER, Peter. Ética Prática. $3^{\text {a }}$ ed. São Paulo: Editora Martins Fontes, 2002.

SLOTERDJIK, Peter. Regras para o parque humano: uma resposta à carta de Heidegger sobre o humanismo. Trad. de José O. de A. Marques. São Paulo: Estação Liberdade, 2000.

VENTURA, Miriam. Direitos Reprodutivos no Brasil. São Paulo, Câmara Brasileira de Livros, 2004. 